ISSN Print: 2074-904X, ISSN Online: 2074-9058

Volume 8, Number 11, November 2016

\title{
International Journal of
}

\section{Intelligent Systems and Applications}

Kol.8

No.11 Nov. 2016

\section{IJISA Vol.8}

Http:// www.mecs-press .org

Vol.8 No.11 November 2016

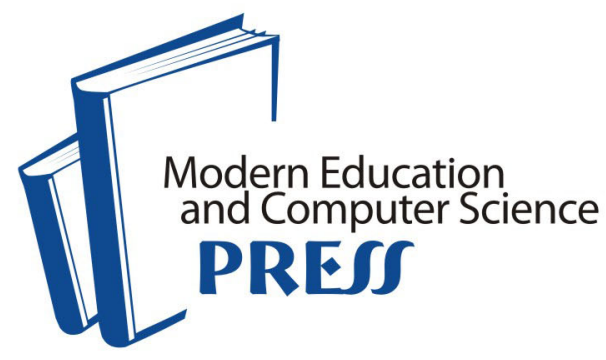


International Journal of Intelligent Systems and Applications (IJISA)

ISSN Print: 2074-904X, ISSN Online: 2074-9058

Volume 8, Number 11, November 2016

\section{Contents}

\section{REGULAR PAPERS}

Agent-Based Buyer-Trader Interaction Model of Traditional Markets

Purba D. Kusuma, Azhari, Reza Pulungan

The Analysis and Investigation of Multiplicative Inverse Searching Methods in the Ring of Integers

Modulo M

Zhengbing Hu, I. A. Dychka, Onai Mykola, Bartkoviak Andrii

Real-Time Fuel Quality Monitoring System for Smart Vehicles

Prerit Saxena, Roop Pahuja, Manmeet Singh Khurana, Sumrit Satija

Enhanced Hopfield Network for Pattern Satisfiability Optimization

Mohd. Asyraf Mansor, Mohd Shareduwan M. Kasihmuddin, Saratha Sathasivam

Improved Krill Herd Algorithm with Neighborhood Distance Concept for Optimization

Prasun Kumar Agrawal, Manjaree Pandit, Hari Mohan Dubey

Application of Intensified Current Search to Multiobjective PID Controller Optimization

Auttarat Nawikavatan, Satean Tunyasrirut, Deacha Puangdownreong

Hybrid Algorithm Based on Swarm Intelligence Techniques for Dynamic Tasks Scheduling in Cloud

Computing

Medhat A. Tawfeek, Gamal F. Elhady

Research on Modeling and Active Steering Control Algorithm for Electric Forklift Steer-by-Wire System 70 Yang Liu, Benxian Xiao 